\title{
TRUTH ASCRIPTIONS, FALSITY ASCRIPTIONS, AND THE PARATACTIC ANALYSIS OF INDIRECT DISCOURSE
}

\author{
SAVAS L. TSOHATZIDIS
}

\begin{abstract}
This paper argues that the obvious validity of certain inferences involving indirect speech reports as premises and truth or falsity ascriptions as conclusions is incompatible with Davidson's so-called "paratactic" analysis of the logical form of indirect discourse. Besides disqualifying that analysis, this problem is also claimed to indicate that the analysis is doubly in tension with Davidson's metasemantic views. Specifically, it can be reconciled neither with one of Davidson's key assumptions regarding the adequacy of the kind of semantic theory he recommends nor with one of his key assumptions regarding the inadequacy of a kind of semantic theory he rejects.
\end{abstract}

Keywords: truth-theoretic semantics; indirect discourse; paratactic analysis; Davidson

The present paper considers certain obviously valid types of inferences involving indirect speech reports as premises and truth or falsity ascriptions as conclusions, and argues that their validity is incompatible with Davidson's so-called "paratactic" analysis of the logical form of indirect discourse (Davidson 1969). It further argues that this particular failure of the Davidsonian analysis has a special significance for Davidson's overall project of using what he terms a "Tarski-style" truth theory as a theory of natural language meaning (Davidson 1967): that project assumes that grasp of the concepts of truth and falsity is essential to natural language interpretation, yet Davidson's analysis cannot characterize as valid certain natural language inferences whose recognition as valid is arguably constitutive of one's grasp of the concepts of truth and falsity. Finally, the paper argues that Davidson's analysis not only has implications that are in tension with his proposed justification for the kind of semantic program he recommends, but, in addition, would require for its defence the explicit adoption of assumptions that are characteristic of a kind of semantic program that he rejects. 
When A is not self-referential, inferences of the following forms are evidently valid:

(i) $\mathrm{S}$ said that $\mathrm{A}, \mathrm{A} \therefore \mathrm{S}$ said something true

(ii) $\mathrm{S}$ said that $\mathrm{A}, \sim \mathrm{A} \therefore \mathrm{S}$ said something false

(iii) $\mathrm{S}$ said that $\sim \mathrm{A}, \sim \mathrm{A} \therefore \mathrm{S}$ said something true

(iv) $\mathrm{S}$ said that $\sim \mathrm{A}, \mathrm{A} \therefore \mathrm{S}$ said something false

For example, in each of the following arguments, the conclusion obviously follows from the premises:

(1) Galileo said that the Earth moves.

The Earth moves.

Therefore, Galileo said something true.

(2) Galileo said that the Earth moves.

The Earth does not move.

Therefore, Galileo said something false.

(3) Galileo said that the Earth does not move.

The Earth does not move.

Therefore, Galileo said something true.

(4) Galileo said that the Earth does not move.

The Earth moves.

Therefore, Galileo said something false.

Not only are such inferences obviously valid, but a person's ability to recognize their validity can plausibly be held to be constitutive of that person's possession of the concepts of truth and falsity: one would not be credited with understanding what truth and falsity are if one was unable to acknowledge that the conclusions of arguments such those in (1)-(4) do indeed follow from their premises. And it is presumably for that reason that Aristotle implicitly appeals to inferences of this sort in order to define truth and falsity, in the famous passage of Metaphysics that many (including Tarski 1944: 3423 ) have regarded as the beginning of sense in inquiries about the concept of truth:

To say of what is that it is not, or of what is not that it is, is false, while to say of what is that it is, or of what is not that it is not, is true (Metaphysics $\Gamma .7$, 1011b26-27; emphasis added $)^{1}$

1 Translation by W. D. Ross, in Barnes 1984. 
It is appropriate, then, to demand of an adequate semantic account of indirect speech reports, and especially of an account that, like Davidson's, purports to be a truth-theoretic one, to be in a position to acknowledge the validity of inferences of this kind. What I propose to argue below is that Davidson's account is not in that position.

As is well known, on Davidson's analysis of indirect speech reports the utterer U of a sentence of the form "S said that P" accomplishes, logically speaking, exactly two things: First, U demonstratively refers by "that" to an utterance of a sentence that has the same form as P but is not part of the indirect speech report (logically speaking, that is, the sentence "S said that P" ends just after the word "that", and that word is a demonstrative pronoun referring to an independently occurring utterance rather than a complementizer introducing a constituent clause). And secondly, $\mathrm{U}$ states that there has been an utterance by $\mathrm{S}$ that has the same content as (and so, in Davidsonian parlance, that 'samesays') the utterance to which U demonstratively refers by using the word "that". Davidson provides the following succinct statement of his analysis, as applied to the indirect speech report "Galileo said that the Earth moves":

The paratactic semantic approach to indirect discourse tells us to view an utterance of 'Galileo said that the Earth moves' as consisting of the utterance of two sentences, 'Galileo said that' and 'The Earth moves'. The 'that' refers to the second utterance, and the first utterance is true if and only if an utterance of Galileo's was the same in content as ('translates') the utterance to which the 'that' refers. (Davidson 1979: 39/1984: 176-7)

For present purposes, there are two points that it is important to keep in mind in considering Davidson's analysis. The first is that, since, according to that analysis, what appear to be subordinate clauses in indirect speech reports are not, in reality, syntactic or semantic parts of those reports at all, but are simply the real word objects to which the demonstrative singular terms allegedly occurring in the reports refer, these clauses cannot be contributed by the reports to any inferences in which the reports occur as premises. To suppose that an argument beginning with the premise "Galileo said that.", where "that" demonstratively refers to an exhibited linguistic object, can properly include that object itself as one of its further premises is no more coherent than to suppose that an argument beginning with the premise "Galileo liked that.", where "that" demonstratively refers to an exhibited painting, can properly include that painting itself as one of its further premises. This means that, on any coherent reconstruction of the arguments in (1)-(4) along Davidsonian lines, the seemingly subordinate 
clauses of the first premises should not be regarded as being transformable into additional independent premises (a transformation that, even if it were not incoherent, would have the unwelcome consequence of producing arguments with redundant premises in the case of (1) and (3), and arguments with inconsistent premises in the case of (2) and (4)), but should simply be excised from the arguments on the grounds that maintaining them as additional independent premises would amount to confusing vehicles of representation with objects of representation. Thus, the only parts of the first premises of (1)-(4) that would survive in a coherent reconstruction of those arguments along Davidsonian lines would be the parts ending with the demonstratively construed "that" - and each one of those parts should be interpreted in the way stipulated by Davidson, i.e. as a statement to the effect that a linguistic object produced by Galileo in the past has the same content as the linguistic object that is being demonstratively referred to by the utterer of "that" in the present.

The second point that it is important to keep in mind in considering Davidson's analysis is that, just as saying, of two objects to which one refers, that they have the same colour, is not saying what their colour is, so saying, of two utterances to which one refers, that they have the same content, is not saying what their content is. If, for example, you know neither Finnish nor Turkish, and someone tells you that a certain Finnish utterance to which he is pointing with his left hand has the same content as a certain Turkish utterance to which he is pointing with his right hand, he has not told you (no matter how sincere towards you he might be and how knowledgeable about Finnish and Turkish he might be) what the content of either the Finnish utterance or the Turkish utterance is. In the same way, saying, as Davidson's analysis does, that, in order for an indirect speech report to be true, the utterance that is thereby attributed to the reported speaker must have the same content as the utterance that is being demonstratively referred to by the reporting speaker, is not saying what the content of either of these utterances is.

To see, now, that the Davidsonian analysis is not in a position to account for the obvious validity of inferences such as (1)-(4), it is sufficient to observe what these inferences would amount to, if the indirect speech reports they contain were interpreted in conformity with the Davidsonian analysis. Let Donald be the person who is uttering the demonstratives that, on the Davidsonian analysis, the inferences contain. Then, from the viewpoint of the Davidsonian analysis, the inference in (1) is tantamount to an inference (call it (D-1)) in which, from the premises that the Earth moves, and that Galileo has produced an utterance that has the same content as the utterance object that is currently being demonstratively referred to by Donald, it is concluded that Galileo said something true. And the inference in (2) is tantamount to an inference (call it (D-2)) in which, from the premises that the Earth does not move, and that Galileo has produced an utterance that 
has the same content as the utterance object that is currently being demonstratively referred to by Donald, it is concluded that Galileo said something false. (Analogous reformulations would be easy to provide for the remaining two cases.)

It is evident, however, that inferences such as (D-1) or (D-2) are not valid: From the statement that the Earth moves (or that the Earth does not move), and that Galileo has produced an utterance identical in content to the utterance object that is currently being demonstratively referred to by Donald, nothing whatsoever follows about the truth (or falsity) of anything said by Galileo. Of course, something might be capable of being shown to follow if, from the statement that Galileo has produced an utterance identical in content to the utterance object that is currently being demonstratively referred to by Donald, one could deduce what the content of Galileo's utterance was. As already noted, however, from the statement that two utterances are identical in content one cannot deduce what the content of either is; and so, the statement that the utterance produced by Galileo in the past and the utterance that is the object of Donald's current demonstration have the same content no more allows one to deduce what the content of either of these utterances is than the statement that a demonstratively referred to utterance of Finnish and a demonstratively referred to utterance of Turkish are identical in content allows one to deduce what the content of either the Finnish utterance or the Turkish utterance is.

Davidson's analysis of indirect speech reports, therefore, cannot avoid regarding as invalid certain obviously valid inferences involving such reports. And it cannot avoid this precisely because of what Davidson has described as its "novel" claim "upon [which] everything depends" - namely, that

from a semantic point of view the content-sentence in indirect discourse [i. e. the sentence following 'said that' in an indirect speech report, SLT] is not contained in the sentence whose truth counts, i. e. the sentence that ends with 'that'. (Davidson 1969: 143/1984: 106; emphasis added)

For, if what follows "said that" in the first premises of the inferences in (1)-(4) is semantically not part of those premises, then there can be no semantic relation whatsoever between those premises and the second premises of (1)-(4). If, however, there is no semantic relation whatsoever between the first and the second premises of (1)-(4), there is no way for the conclusions of (1)-(4) to follow from their premises, and the inferences must accordingly be held to be invalid. Given, then, that the inferences are clearly valid, and that the least that one would expect from a satisfactory account of the logical form of indirect speech reports is that it enable one to represent as valid all clearly valid inferences in which such reports occur as premises, the conclusion must be that Davidson's account fails as an account of the logical form of indirect speech reports. 
Though the problem exposed above is by no means the only problem that Davidson's account faces, it has a special significance that distinguishes it from several other problems that have been raised and discussed in the literature that the account has so far generated (for an overview of that literature, written from a perspective sympathetic to Davidson, see Sennet 2013). As is well known, the entire Davidsonian program in natural language semantics rests on the assumption that what Davidson describes as a "Tarski-style" truth theory for a natural language could serve as a theory of meaning for that language, in the sense that a person's knowledge of that truth theory would suffice for that person's interpreting the utterances of the language's users. ${ }^{2}$ It can plausibly be held, however, that a person will not be able to understand what a truth theory states if it has no idea what truth and falsity are, and that it will have no idea what truth and falsity are if it is unable to recognize, among other things, that certain inferences involving the truth and falsity predicates, such as those exemplified in (1)-(4), are valid. And since, as argued above, a person who understands indirect speech reports in accordance with Davidson's "paratactic" account will not be able to recognize that inferences such as (1)-(4) are valid, it follows that it will not be a person capable of understanding what truth and falsity are and, therefore, of using a truth theory of the sort envisaged by Davidson in order to interpret the utterances of others. It appears, then, that inferences of the sort we have been considering are significant not only by virtue of showing that Davidson's account of the logical form of indirect speech reports is, considered in itself, unsuccessful, but also by virtue of showing that that account is in tension with one of the fundamental assumptions of the Davidsonian semantic program.

It may finally be noted that Davidson's analysis of indirect speech reports not only has implications that, as just seen, are in tension with his proposed justification for the kind of semantic program that he recommends, but, in addition, would require for its defence the explicit adoption of assumptions that are characteristic of a kind of semantic program that he rejects. It is well known that Davidson denies that a theory of translation can serve as a theory of interpretation (and so, as a theory of meaning in his sense), and that the main reason he offers for this denial is that

2 Notice that, as Davidson acknowledges (1973: 321/1984: 134), this assumption reverses what Tarski was taking to be the proper order of explanation: The "Tarski-style" theory envisaged by Davidson is supposed to elucidate the concept of meaning by taking the concept of truth for granted, whereas Tarski's actual theory of truth was supposed to elucidate the concept of truth by taking the concept of meaning for granted. 
we can know which sentences of the subject language translate which sentences of the object language without knowing what any of the sentences of either language mean (Davidson 1973: 317/1984:129)

But this Davidsonian objection to translational theories of interpretation has fundamentally the same source as the objection that, as we saw, can and should be raised, in view of the problem posed by inferences such as those in (1)-(4), against Davidson's own analysis of indirect discourse. For, as previously argued, the obvious validity of these inferences could not be held to be consistent with what the Davidsonian analysis of indirect discourse stipulates unless one were to mistakenly suppose that stating that two expressions have the same meaning is the same thing as stating what their meaning is. So, the mistake that, according to Davidson, one would be making if one were to suppose that a theory of translation can serve as a theory of interpretation is precisely the mistake that one would have to make if one were to suppose that the validity of inferences such as (1)-(4) is consistent with his analysis of indirect discourse. It seems, therefore, that an extra reason that, in view of such inferences, Davidson would have for abandoning the "paratactic" analysis is that abandoning it would allow him to maintain his principal argument in favour of the thesis that a theory of translation cannot serve as a theory of interpretation.

The fact that Davidson has not, apparently, realized that his "paratactic" analysis of indirect discourse cannot be held conjointly with his objection to translational theories of interpretation may of course be due simply to the fact that he didn't happen to consider the role of indirect speech reports in inferences such as those in (1)-(4). For it is the role of indirect speech reports in such inferences that makes especially clear what might otherwise not be apparent, namely, that it is one thing to say, as the "paratactic" analysis does, that a certain demonstrated utterance is "the same in content as ('translates')" a certain attributed utterance (1979: 39/1984: 177) and quite another to say what the content of either of these utterances is. It may also be, however, that Davidson was, at least intermittently, under the confused impression that saying the former of these things is the same as saying the latter, and was thus led to the mistake of supposing that his analysis does provide what it ought to provide but does not in fact provide. Thus, at one point in which he purports to be informally explicating the "paratactic" analysis, Davidson says that, on that analysis, "what follows [the demonstrative 'that'] gives the content of the subject's saying" (Davidson 1969:142/1984:106). As we have seen, however, what the "paratactic" analysis actually claims is not that the reporting speaker's demonstrative "that" refers to an utterance that 'gives the content' of an utterance attributed to the reported speaker; rather, what it claims is only that the reporting speaker's demonstrative "that" refers to an utterance that is "the same in content as ('translates')" an utterance attributed to the reported speaker. 
And these two claims can be held to equivalent only by someone who commits the error that, according to Davidson himself, proponents of translational theories of interpretation would be committing - in other words, only by someone who fails to realize that saying of two utterances that they have the same content is not the same thing as 'giving the content' of either (i.e. is not the same thing as saying what the content of either is). I suspect that this is not the only case where what a Davidsonian analysis actually offers is not the same thing as what it is advertised by Davidson as offering, and that an examination of similar cases in other places of Davidson's oeuvre might be instructive. ${ }^{3}$

\author{
Savas L. TsohATZIDIS \\ Department of Linguistics \\ Faculty of Philosophy \\ Aristotle University of Thessaloniki \\ 54124 Thessaloniki \\ Greece \\ E-Mail: savasts@auth.gr
}

\title{
References
}

BARnes, Jonathan (ed.) 1984. The Complete Works of Aristotle: The Revised Oxford Translation, 2 Vols, Princeton, NJ: Princeton University Press.

Davidson, Donald 1967. Truth and meaning. Synthese 17, 304-323.

DAVIDSON, Donald 1969. On saying that. Synthese 19, 130-146.

DAVIDSOn, Donald 1973. Radical interpretation. Dialectica 27, 313-328.

Davidson, Donald 1979. Reply to Foster. In Gareth Evans and John McDowell (eds), Truth and Meaning: Essays in Semantics, Oxford: Clarendon Press, 33-41.

Davidson, Donald 1984. Inquiries into Truth and Interpretation. Oxford: Oxford University Press.

Sennet, Adam 2013. Parataxis. In Ernie Lepore and Kirk Ludwig (eds), A Companion to Donald Davidson, Oxford: Wiley Blackwell, 191-207.

TARSKI, Alfred 1944. The semantic conception of truth and the foundations of semantics. Philosophy and Phenomenological Research 4, 341-376.

${ }^{3}$ I would like to thank the present paper's anonymous referees for their valuable comments. 